\title{
Synthesis of PLGA nanoparticles of tea polyphenols and their strong in vivo protective effect against chemically induced DNA damage
}

This article was published in the following Dove Press journal:

International Journal of Nanomedicine

13 April 2013

Number of times this article has been viewed

\author{
Amit Kumar Srivastava' \\ Priyanka Bhatnagar ${ }^{2}$ \\ Madhulika Singh' \\ Sanjay Mishra' \\ Pradeep Kumar ${ }^{2}$ \\ Yogeshwer Shukla' \\ Kailash Chand Gupta ${ }^{1,2}$ \\ 'Proteomics Laboratory, Indian \\ Institute of Toxicology Research \\ (CSIR), Lucknow, India; ${ }^{2}$ Nucleic Acid \\ Research Laboratory, Institute of \\ Genomics and Integrative Biology \\ (CSIR), Delhi University Campus, India
}

Correspondence: Yogeshwer Shukla Proteomics Laboratory, Indian Institute of Toxicology Research (CSIR),

PO Box 80, MG Marg,

Lucknow UP 22600I, India

Tel +9l 5222963827

Fax +9| 5222628227

Email yshukla@iitr.res.in

\begin{abstract}
In spite of proficient results of several phytochemicals in preclinical settings, the conversion rate from bench to bedside is not very encouraging. Many reasons are attributed to this limited success, including inefficient systemic delivery and bioavailability under in vivo conditions. To achieve improved efficacy, polyphenolic constituents of black (theaflavin [TF]) and green (epigallocatechin-3-gallate [EGCG]) tea in poly(lactide-co-glycolide) nanoparticles (PLGA-NPs) were entrapped with entrapment efficacy of $\sim 18 \%$ and $26 \%$, respectively. Further, their preventive potential against 7,12-dimethylbenzanthracene (DMBA)-induced DNA damage in mouse skin using DNA alkaline unwinding assay was evaluated. Pretreatment (topically) of mouse skin with either TF or EGCG (100 $\mu \mathrm{g} /$ mouse) doses exhibits protection of $45.34 \%$ and $28.32 \%$, respectively, against DMBA-induced DNA damage. However, pretreatment with TF-loaded PLGA-NPs protects against DNA damage $64.41 \%$ by $1 / 20$ th dose of bulk, $71.79 \%$ by $1 / 10$ th dose of bulk, and $72.46 \%$ by $1 / 5$ th dose of bulk. Similarly, $51.28 \%$ (1/20th of bulk), $57.63 \%$ (1/10th of bulk), and 63.14\% (1/5th of bulk) prevention was noted using EGCG-loaded PLGA-NP doses. These results showed that tea polyphenol-loaded PLGA-NPs have $\sim 30$-fold dose-advantage than bulk TF or EGCG doses. Additionally, TF- or EGCG-loaded PLGA-NPs showed significant potential for induction of DNA repair genes (XRCC1, XRCC3, and ERCC3) and suppression of DNA damage responsive genes ( $p 53, p 21, M D M 2, G A D D 45 \alpha$, and $C O X-2)$ as compared with respective bulk TF or EGCG doses. Taken together, TF- or EGCG-loaded PLGA-NPs showed a superior ability to prevent DMBA-induced DNA damage at much lower concentrations, thus opening a new dimension in chemoprevention research.
\end{abstract}

Keywords: DNA alkaline unwinding assay, mouse skin, DNA repair

\section{Introduction}

Gene transposition is a well known phenomenon in prokaryotic and eukaryotic cells. ${ }^{1}$ DNA is quite frequently subjected to alterations in chemistry or sequence of individual nucleotides. Many of these changes are attributed to the errors introduced during replication, recombination, and self-repair. The DNA of the living cell reacts easily with a variety of chemicals and physical agents, many of which are present in our environmental and occupational settings. These reactions may cause mutations and can lead to the development of cancer. ${ }^{2}$

Tea has been consumed as a popular beverage worldwide since ancient times because of its health-promoting effects and pleasant aroma. Beverage-grade commercial tea is manufactured from the leaves of the plant Camellia sinensis and is commercially available, mainly in three forms: green, black, and oolong tea. ${ }^{3,4} \mathrm{Of}$ the total commercial tea production worldwide, about $78 \%$ of tea is consumed in 
the form of black tea, mainly in Europe and many Asian countries, and $20 \%$ is consumed in the form of green tea. ${ }^{3}$ Green tea is produced from the unfermented leaves of Camellia sinensis, and polyphenols, known as catechins, constitute its principal chemical constituent. The major catechins contained in green tea are (-)-epicatechin, (-)-epicatechin-3-gallate, (-)-epigallocatechin, and (-)-epigallocatechin-3-gallate (EGCG). ${ }^{5}$ Black tea is made by extensive enzymatic oxidation of these polyphenols, which leads to the formation of theaflavins (TFs). The principal TFs in black tea are TF-3-gallate, TF-3'-gallate, and TF-3-3' -digallate. ${ }^{6}$ Tea and its polyphenols, in particular, have been shown to inhibit cancer at different organ sites in several animal models. ${ }^{7,8}$ Many mammalian models have shown that both black and green tea polyphenols, play an important role in the inhibition of skin carcinogenesis. ${ }^{9,10}$ Previous reports from the authors' lab have shown the chemopreventive potential of tea polyphenols in both in vivo and in vitro conditions. ${ }^{11,12}$

Chemoprevention through the use of naturally occurring phytochemicals has emerged as a successful strategy for cancer prevention and treatment. ${ }^{13}$ But one major drawback associated with these phytochemicals is their inefficient systemic delivery and bioavailability under in vivo conditions; hence, the applicability of chemoprevention to humans has met with limited success. To improve the bioavailability of the chemopreventive agents, a new concept of nanomedicine has been introduced. ${ }^{14}$ The reduced dimensions of nanostructures lend them to targeted diagnostic and therapeutic practices that enable treatment with greater accuracy and less discomfort. Nowadays, the concept of nanomedicine is being used and assessed in different areas of cancer prevention and treatment. In cancer therapy, nanotized anticancer drugs are encapsulated/conjugated with an ideal carrier which enhances the targeted delivery and bioavailability of the drug. ${ }^{15}$ The colloidal carriers based on biodegradable and biocompatible polymeric systems have largely influenced the controlled and targeted drug-delivery concept. Among several known carriers, poly(lactide-co-glycolide) (PLGA) 50:50 has gained importance for the encapsulation of a wide variety of drugs as it is biodegradable, biocompatible, capable of controlling the release of the incorporated entity, and less toxic. ${ }^{16,17}$ The choice of PLGA was also supported by the fact that it can be used to form stable nanoparticles (NPs), and has already been approved for use in humans by the US Food and Drug Administration. ${ }^{18}$ Thus, it has been chosen as the polymer scaffold to fabricate the NPs used in the present study.
Mammalian skin forms a hurdle between the host and surrounding environments. ${ }^{19,20}$ However, it is also a major route of entry for several toxic agents and a potential target of environmental hazards, which can cause several skin-related abnormalities including skin cancer. ${ }^{21}$ Epidemiological studies suggest that almost one-third of all new cancers diagnosed annually worldwide originate from skin. ${ }^{22}$ Several studies show an association between different human cancers and lifestyle/dietary habits; additionally, detailed studies of mutational events in human cancers have provided evidence for a direct involvement of environmental mutagens/carcinogens in the progression of different types of cancer. ${ }^{23,24}$

In the present study, a PLGA-based drug development strategy was followed to encapsulate TF and EGCG. The authors envisioned that NPs-mediated delivery of bioactive catechins from black tea (TF) and green tea (EGCG) could be useful in enhancing their protective potential against 7,12dimethylbenz[a]anthracene (DMBA)-induced DNA damage in mouse skin tissue.

\section{Materials and methods \\ Chemicals}

PLGA 50:50 (molecular weight [MW] 40-75 kDa), polyvinyl alcohol (MW $30 \mathrm{kDa}$ ), EGCG, TF, and DMBA were purchased from Sigma-Aldrich (St Louis, MO, USA). Hydroxylapatite and N,N-dimethylformamide were purchased from Sisco Research Laboratory (Mumbai, India). All other chemicals used were of analytical grade purity and procured locally.

\section{Formulation of TF- or EGCG-loaded PLGA-NPs}

TF- or EGCG-loaded PLGA-NPs were prepared using the standard solvent evaporation method, ${ }^{25}$ with minor modifications. Briefly, a $0.5 \mathrm{~mL}$ aqueous solution of TF or EGCG (20 mg) was added to $2 \mathrm{~mL}$ PLGA (100 mg) solution in dichloromethane and was placed on a Heidolph MR Hei-Tec magnetic stirrer (Heidolph Instruments, Schwabach, Germany) at $210 \times g$. The resulting oil-in-water primary emulsion was then stirred at $210 \times g$ for 2 hours at room temperature. The resulting emulsion was then poured into aqueous solution of polyvinyl alcohol $(1 \%, 4 \mathrm{~mL}, \mathrm{w} / \mathrm{v})$, with constant stirring at $210 \times g$ to obtain a water-in-oil-in-water secondary emulsion, and finally the organic solvent was evaporated by constant stirring at $8-13 \times g$ on a magnetic stirrer. This resulted in nanoprecipitation and formation of NPs. Subsequently, the solution was subjected to centrifugation at $13,600 \times g$ by using a Heraeus Multifuge $3 \mathrm{SR}+$ centrifuge (Thermo Fisher Scientific, Waltham, MA, USA), followed 
by washing with water, and finally, the NPs were freezedried with a Univapo $150 \mathrm{H}$ Unicryo freeze dryer (Uniequip, Martinsried, Germany) to obtain a solid dry powder. The NPs obtained in this process were stored at $4^{\circ} \mathrm{C}$ under anhydrous conditions until used for further studies.

\section{Characterization of the NPs Percentage yield}

Percentage yield of the NPs was calculated after a constant weight had been obtained, by using the following formula:

$$
\begin{aligned}
\% \text { Yield }= & \text { weight of NPs } \\
& /(\text { weight } \text { of drug }+ \text { polymer }) \times 100 .
\end{aligned}
$$

\section{Measurements of NP size and zeta potential}

The mean particle size and distribution, as well as the zeta potential of the TF- or EGCG-loaded PLGA-NPs was determined by a dynamic light scattering technique using a Zetasizer Nano-ZS (Malvern Instruments, Malvern, UK) employing a nominal $5 \mathrm{~mW} \mathrm{He-Ne} \mathrm{laser} \mathrm{operating} \mathrm{at}$ $633 \mathrm{~nm}$ wavelength. The freeze-dried NPs were dispersed in phosphate buffer ( $\mathrm{pH} 7.2-7.4$ ), $1 \mathrm{mg} / \mathrm{mL}$, and the size and zeta potential were measured as the average of 20 and 30 runs in triplicate, respectively. The data analysis was performed in automatic mode and the average values were estimated by Smoluchowski approximation from the electrophoretic mobility. ${ }^{26}$

\section{Drug loading and entrapment efficiency}

Drug loading and entrapment efficiency of TF- or EGCG-loaded PLGA-NPs was determined by spectrophotometric estimation using Lambda Bio 20 UV/VIS Spectrophotometer (Perkin Elmer, Waltham, MA) as follows. A known amount of NPs (10 mg, dry powder) was dissolved in $1 \mathrm{~mL}$ acetonitrile solution to solubilize the polymer and precipitate the tea polyphenols. The samples were centrifuged at $13,600 \times g$ for 20 minutes twice, and the pellet was dissolved in $1 \mathrm{~mL}$ distilled water. The absorbance of the solution was measured at $273 \mathrm{~nm}$. The amount of tea polyphenols was calculated from the standard curve drawn between the varied amount of tea polyphenols and absorbance (optical density). The drug-loading (\%DL) and entrapment efficiency $(\% \mathrm{EE})$ in percentage was calculated using the following formula. All the measurements were conducted in triplicate.

$$
\% \mathrm{DL}=(\text { mass of drug in NPs } / \text { mass of NPs }) \times 100
$$

$$
\begin{aligned}
\% \mathrm{E}= & \text { (amount of tea polyphenols in polymeric NPs } \\
& \text { /amount of tea polyphenols used }) \times 100 .
\end{aligned}
$$

\section{Transmission electron microscopy (TEM)}

The surface morphology of the NPs was obtained using TEM. Briefly, a drop of aqueous solution of lyophilized powder $(1 \mathrm{mg} / \mathrm{mL})$ was placed on a TEM grid surface with a filter paper (Whatman No. 1). A drop of $1 \%$ uranyl acetate was added to the surface of the fomwar-coated grid. After 1 minute of incubation, excess fluid was removed, and the grid surface was air dried at room temperature before being loaded into a transmission electron microscope (FEI Company, Hillsboro, OR, USA), operated at $80 \mathrm{kV}$, and attached to a Gatan DigitalMicrograph ${ }^{\mathrm{TM}}$ (Gatan Inc, Pleasanton, CA, USA).

\section{Evaluation of TF or EGCG release from NPs}

TF- or EGCG-loaded PLGA-NPs were evaluated for their in vitro release kinetics. Since, TF and EGCG are soluble in water, free tea polyphenols released in aqueous buffer can easily be quantified spectrophotometrically. A known quantity of lyophilized PLGA-NPs (10 mg) was dispersed in $1 \mathrm{~mL}$ phosphate buffer, $\mathrm{pH} 7.4$, and was kept in a Heidolph Unimax 1010 incubator shaker (Heidolph Instruments) maintained at $37^{\circ} \mathrm{C} \pm 0.5^{\circ} \mathrm{C}$, with constant stirring. At predetermined intervals of time, the solution was centrifuged at $2000 \times g$ for 10 minutes to collect the supernatant, and its absorbance was measured at $273 \mathrm{~nm}$. An equal amount of buffer was added to the pellet and the release study was continued. The quantity of the released drug was then calculated using a previously drawn standard curve of the pure drugs in phosphate buffer.

\section{Animal bioassay}

Swiss albino mice (female, 20-22 g bodyweight) were obtained from the Indian Institute of Toxicology Research (Lucknow, India) animal breeding colony. Ethical approval for the experiment was obtained from the institutional ethical committee. The animals were housed in polypropylene cages at a density of five animals per cage on woodchip bedding in an air-conditioned (temperature $23^{\circ} \mathrm{C} \pm 2{ }^{\circ} \mathrm{C}$, relative humidity $55 \% \pm 5 \%$ ) animal room. Animals were quarantined for 1 week on a 12/12 hour light/dark cycle and were fed a solid pellet diet (Ashirwad, Chandigarh, India). The animals were divided into 12 groups consisting of 15 animals each. Bulk or tea polyphenol-loaded PLGA-NPs were applied topically in the shaved interscapular region 
of $2 \mathrm{~cm}^{2}$. DMBA ( $52 \mu \mathrm{g} / \mathrm{mouse}$ ) was applied topically (once only) at the same site, after 1 hour of bulk or nanotized tea polyphenols. The treatments were given as follows:

Group I No treatment (untreated control).

Group II DMBA ( $52 \mu \mathrm{g} / \mathrm{mouse}$, once only) was topically applied to the animals.

Group III Animals were topically applied with bulk TF (100 $\mu \mathrm{g} /$ mouse), 1 hour prior to DMBA treatment.

Group IV Animals were topically applied with TF-loaded PLGA-NPs at $5 \mu \mathrm{g} /$ mouse (1/20th of bulk), 1 hour prior to DMBA treatment.

Group V Animals were topically applied with TF-loaded PLGA-NPs at $10 \mu \mathrm{g} / \mathrm{mouse}$ (1/10th of bulk), 1 hour prior to DMBA treatment.

Group VI Animals were topically applied with TF-loaded PLGA-NPs at $20 \mu \mathrm{g} /$ mouse (1/5th of bulk), 1 hour prior to DMBA treatment.

Group VII Animals were topically applied with bulk EGCG $(100 \mu \mathrm{g} /$ mouse $), 1$ hour prior to DMBA exposure.

Group VIII Animals were topically applied with EGCGloaded PLGA-NPs at $5 \mu \mathrm{g} /$ mouse $(1 / 20$ th of bulk), 1 hour prior to DMBA treatment.

Group IX Animals were topically applied with EGCGloaded PLGA-NPs at $10 \mu \mathrm{g} /$ mouse $(1 / 10$ th of bulk), 1 hour prior to DMBA treatment.

Group X Animals were topically applied with EGCGloaded PLGA-NPs at $20 \mu \mathrm{g} /$ mouse $(1 / 5$ th of bulk), 1 hour prior to DMBA treatment.

Group XI Animals were topically applied with TF-loaded PLGA-NPs at $20 \mu \mathrm{g} /$ mouse (1/5th of bulk), alone.

Group XII Animals were topically applied with EGCGloaded PLGA-NPs at $20 \mu \mathrm{g} /$ mouse $(1 / 5$ th of bulk), alone.

Animals from all groups were sacrificed humanely after 24 hours of treatment, and skin was excised for further study.

\section{DNA alkaline unwinding assay (DAUA) in mouse skin tissue}

DNA damage is reported to decrease the quantity of double-stranded (ds)-DNA following alkaline denaturing. ${ }^{27}$ The DAUA measures the amount of primary DNA damage based upon the fraction of single-stranded (ss) and ds-DNA. Hydroxyapatite batch procedure was used for measuring strand breaks in cellular DNA as described earlier. ${ }^{28}$ In short, the DNA isolation from mouse skin was carried out by the salting out procedure. DNA (100 $\mu \mathrm{g})$ was subjected to alkaline unwinding for 1 hour in a dark chamber. The $\mathrm{pH}$ of the reaction mixture was then neutralized ( $\mathrm{pH} 7.0$ ) with $0.07 \mathrm{~N} \mathrm{HCl}$. Then, $20 \mu \mathrm{M}$ EDTA containing $2 \%$ sodium dodecyl sulfate was added, and the resultant mixture was transferred to tubes containing 0.5 $\mathrm{M}$ potassium phosphate buffer, $\mathrm{pH} 7.0$, and 10\% formamide. The samples were incubated at $60^{\circ} \mathrm{C}$ for 2 hours with intermitted vortexing. At the end of the alkaline unwinding, the relative amount of ds- and ss-DNA present was quantified. The ss- and ds-DNA were selectively eluted from the hydroxyapatite column by using $0.125 \mathrm{M}$ potassium phosphate buffer, pH 7.0, containing 20\% formamide and $0.5 \mathrm{M}$ potassium phosphate buffer, $\mathrm{pH} 7.0$, containing $20 \%$ formamide, respectively. Further, DNA in the elutes was measured by taking absorbance at $260 \mathrm{~nm}$, and strand breaks were calculated by using the equation:

$$
\ln \mathrm{F}=-\left(\mathrm{k} / \mathrm{M}_{\mathrm{n}}\right) t^{\beta}
$$

where $\mathrm{F}$ is the fraction of remaining ds-DNA after alkali treatment for the time $t, \mathrm{M}_{\mathrm{n}}$ is the number-average molecular weight between two breaks, and $\beta$ is a constant that is less than 1 . The number of unwinding points $(\mathrm{P})$ per alkaline unwinding unit of DNA were measured by using the equation:

$$
\mathrm{P}=\operatorname{lnF}_{\mathrm{x}} / \ln \mathrm{F}_{0}
$$

where $\mathrm{F}_{\mathrm{x}}$ and $\mathrm{F}_{0}$ are the fractions of ds-DNA remaining after alkaline denaturation of treated and control samples, respectively. The number of breaks (n) per unit DNA were then determined using the equation:

$$
\mathrm{n}=\mathrm{P}-1
$$

\section{Reverse transcriptase polymerase chain reaction (RT-PCR)}

Total RNA was extracted from the control and treated skin tissue samples with the TRIzol ${ }^{\circledR}$ system (Molecular Research Center, Inc, Cincinnati, OH, USA), as per manufacturer's instructions. RT-PCR was conducted as described by Arora et al. ${ }^{29}$ In brief, complementary DNA was prepared using a $3 \mu \mathrm{g}$ RNA sample, adding $1 \mu \mathrm{g}$ oligo(dT) $)_{18}, 0.5 \mathrm{mM}$ deoxyribonucleotide triphosphate (dNTP), and $200 \mathrm{U}$ of Revert Aid ${ }^{\mathrm{TM}}$ H Minus M-MuLV RT enzyme (MBI Fermentas, Hanover, MD, USA). PCR was performed using selective mouse primers (Supplementary Table 1) (synthesized at Integrated DNA 
Table I Characteristics of TF/EGCG loaded-NPs

\begin{tabular}{llllll}
\hline Nanoparticles & \% Yield & $\begin{array}{l}\text { Size }(\mathbf{n m}) \\
(\text { PDI) }\end{array}$ & $\begin{array}{l}\text { Zeta potential } \\
(\mathbf{m V})\end{array}$ & $\begin{array}{l}\text { Drug Loading } \\
(\%)\end{array}$ & $\begin{array}{l}\text { Encapsulation } \\
\text { Efficiency }(\%)\end{array}$ \\
\hline EGCG-PLGA & 96.90 & $127.2 \pm 12(0.189)$ & $-24.5 \pm 1.89$ & 5.76 & $\sim 26$ \\
TF-PLGA & 79.20 & $129.6 \pm 14(0.098)$ & $-20.2 \pm 0.91$ & 3.38 & $\sim 18$ \\
\hline
\end{tabular}

Note: Mean diameter and Zeta potential in phosphate buffer $(\mathrm{pH} 7.4)$ measured by DLS.

Abbreviation: PDI, polydispersity index.

Technologies, Inc, Coralville, IA, USA) on $2 \mu \mathrm{L}$ of RT product incubated with $1 \mathrm{U}$ of Taq DNA polymerase in a $25 \mu \mathrm{L}$ reaction mixture containing $1 \mathrm{mM}$ dNTP, $1.5 \mathrm{mM} \mathrm{MgCl}$ (MBI Fermentas). The amplified fragments were detected in $2 \%(\mathrm{w} / \mathrm{v})$ agarose gel and analyzed on an IS1000 image analysis system (Alpha Innotech, San Leandro, CA, USA).

\section{Statistical analysis}

The data was analyzed for mean values and standard deviation (mean $\pm \mathrm{SD}$ ) for all groups. Statistically significant differences were determined between control and treatment groups using one-way analysis of variance (SPSS software version 14.0) followed by Dunnett post-hoc test. Values with $P<0.05$ were considered significant.

\section{Results}

\section{Percentage yield, entrapment efficiency, drug loading, particle size, and zeta potential}

In a NP formulation, polyvinyl alcohol (PVA) solution acts as a stabilizer. Various concentrations of PVA were studied for formation of NPs, and finally the formulation was optimized at $1 \%$ PVA concentration. This resulted in formation of the small sized and evenly distributed NPs with optimum entrapment,

A

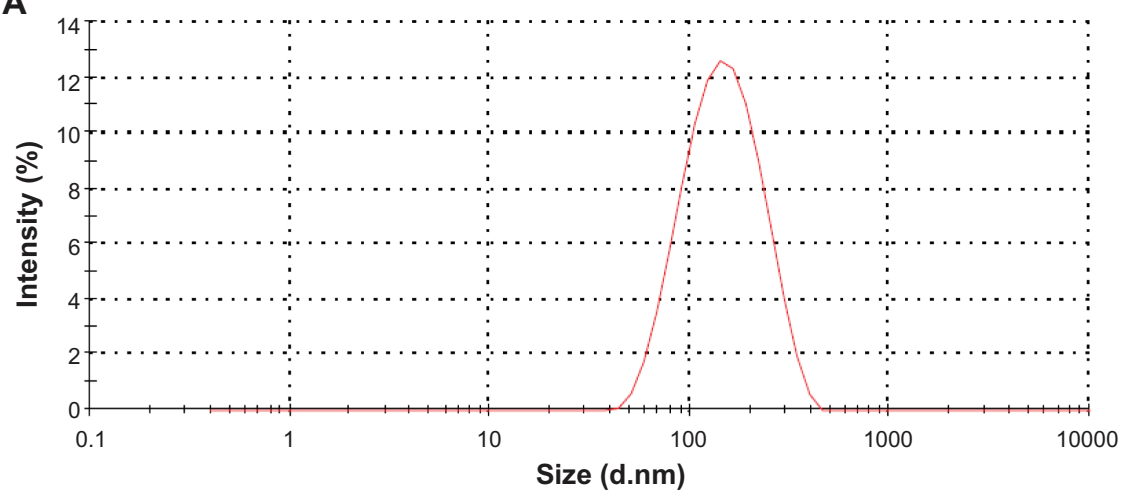

B

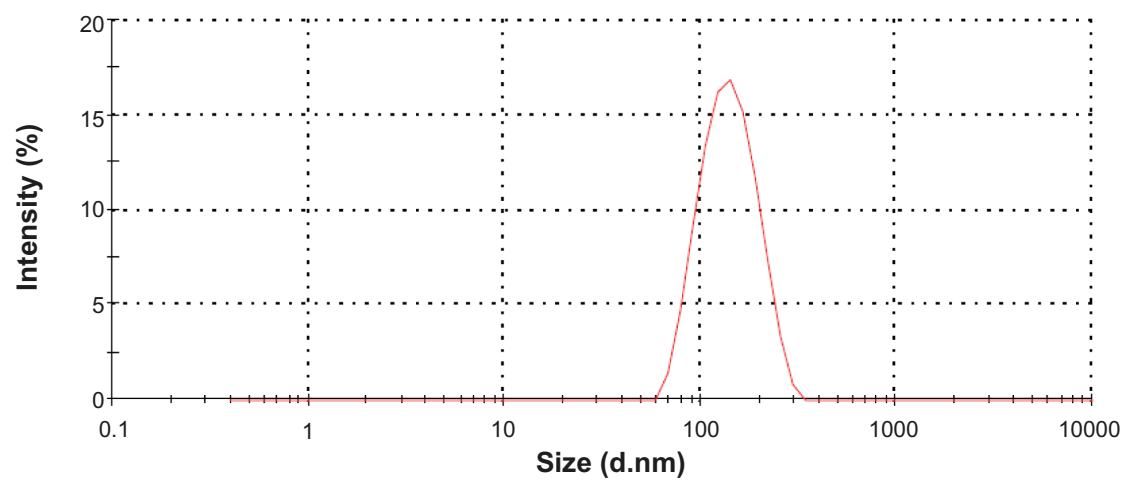

Figure I Particle size distribution of epigallocatechin-3-gallate (A) and theaflavin (B) nanoparticles. Note: Values are represented as mean \pm standard deviation. 
having all the properties required for systemic delivery of tea polyphenols. The yield of the NPs prepared was found to be high at $79.20 \%$ and $96.90 \%$ for TF- and EGCG-loaded PLGA-NPs, respectively. The corresponding encapsulation efficiency of the NPs was $\sim 18 \%$ and $\sim 26 \%$, and the average loading was around $3.38 \%$ and $5.76 \%$ of the polymer weight, respectively. The particle size of the NPs was determined by dynamic light scattering. Figure 1 depicts the formation of near monodisperse PLGA-NPs, with the mean particle size being $129.60 \mathrm{~nm}$ (polydispersity index [PDI] $=0.098$ ) for TF-loaded PLGA-NPs and $127.20 \mathrm{~nm}$ (PDI = 0.18) for EGCG-loaded PLGA-NPs. The zeta potential of the TF- and EGCG-loaded PLGA-NPs was -20.20 and -24.50 (Table 1).

\section{Surface morphology of NPs}

The surface morphology of the TF- or EGCG-loaded PLGANPs was determined by TEM. TEM scan showed formation of spherical and smooth NPs of both TF and EGCG (Figure 2). The results also confirm that the particles have a more or less uniform size distribution and low polydispersity.

\section{In vitro profile of TF- or EGCG-loaded PLGA-NPs}

The release kinetics for both the tea polyphenols from PLGA-NPs was studied up to 10 days. The release profile of the NPs at $37^{\circ} \mathrm{C}$ in phosphate-buffered saline is shown in Figure 3 . The formulation exhibited sustained and continuous release from the PLGA-NPs as a result of polymer bulk

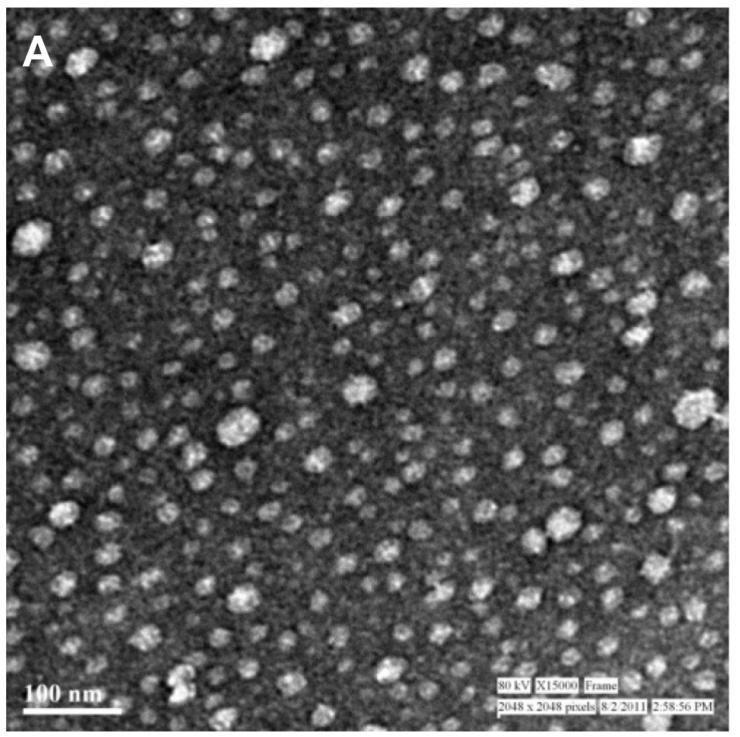

degradation in a homogeneous way due to hydrolysis. ${ }^{30,31}$ The TF and EGCG release from the PLGA-NPs showed the biphasic release pattern, with approximately $25 \%$ and $20 \%$ release of the total tea polyphenols entrapped in 24 hours, respectively, followed by sustained release over the extended period of 10 days $(74.4 \%$ in TF NPs and $89 \%$ in EGCG NPs).

\section{In vivo studies}

\section{Effect of bulks and TF- or EGCG-loaded PLGA-NPs}

on DMBA-induced nick formation in mouse skin

Based on the amount of duplex DNA remaining after alkali treatment for a specified time, the number of strand breaks formed per unit of DNA was determined in this study. Both bulk and nanotized tea polyphenols were found to inhibit DMBA-induced DNA alkylation damage in a dosedependent manner. However, with the lower concentrations of PLGA-loaded NPs (at 1/20th, 1/10th, and 1/5th concentration of bulk tea), reduced numbers of nick formation and significantly higher protective effects as compared with their respective bulk polyphenols were observed (Figure 4). Group I does not show any decrease in the amount of duplex DNA. The results revealed that DMBA, when given at a single dose of $52 \mu \mathrm{g} /$ mouse (Group II) caused significant DNA damage over control (Group I) $(P<0.05)$. Pretreatment of bulk (100 $\mu \mathrm{g} / \mathrm{mouse})$ and TF- or EGCG-loaded PLGA-NPs significantly decreased the DMBA-induced DNA damage in a dose-dependent manner $(P<0.05)$. Figure 4 shows the kinetics of DMBA induced DNA strand break protection at a

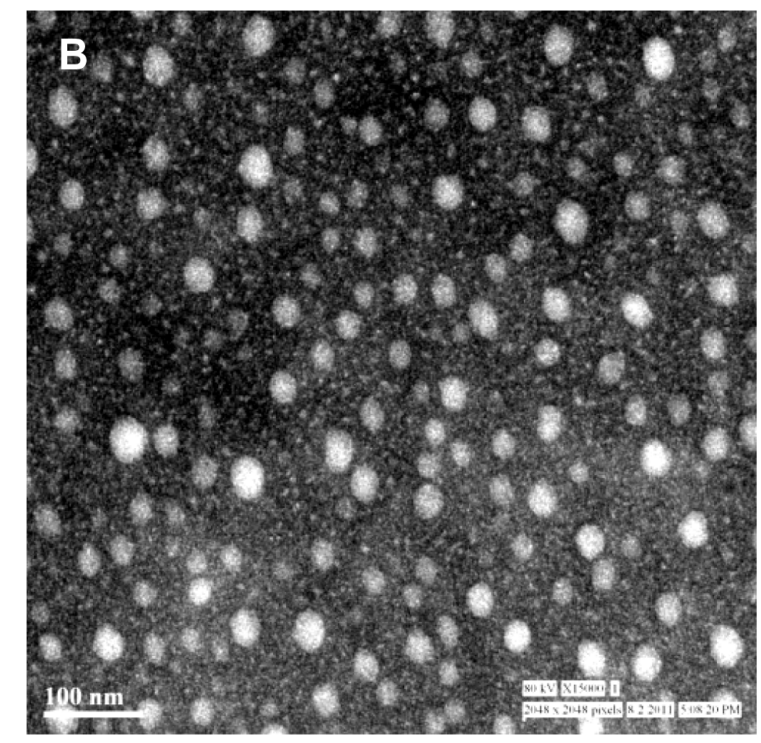

Figure 2 Transmission electron microscopy of theaflavin-loaded PLGA-NPs (A) and epigallocatechin-3-gallate-loaded PLGA-NPs (B). Abbreviation: PLGA-NP, poly(lactide-co-glycolide) nanoparticle. 

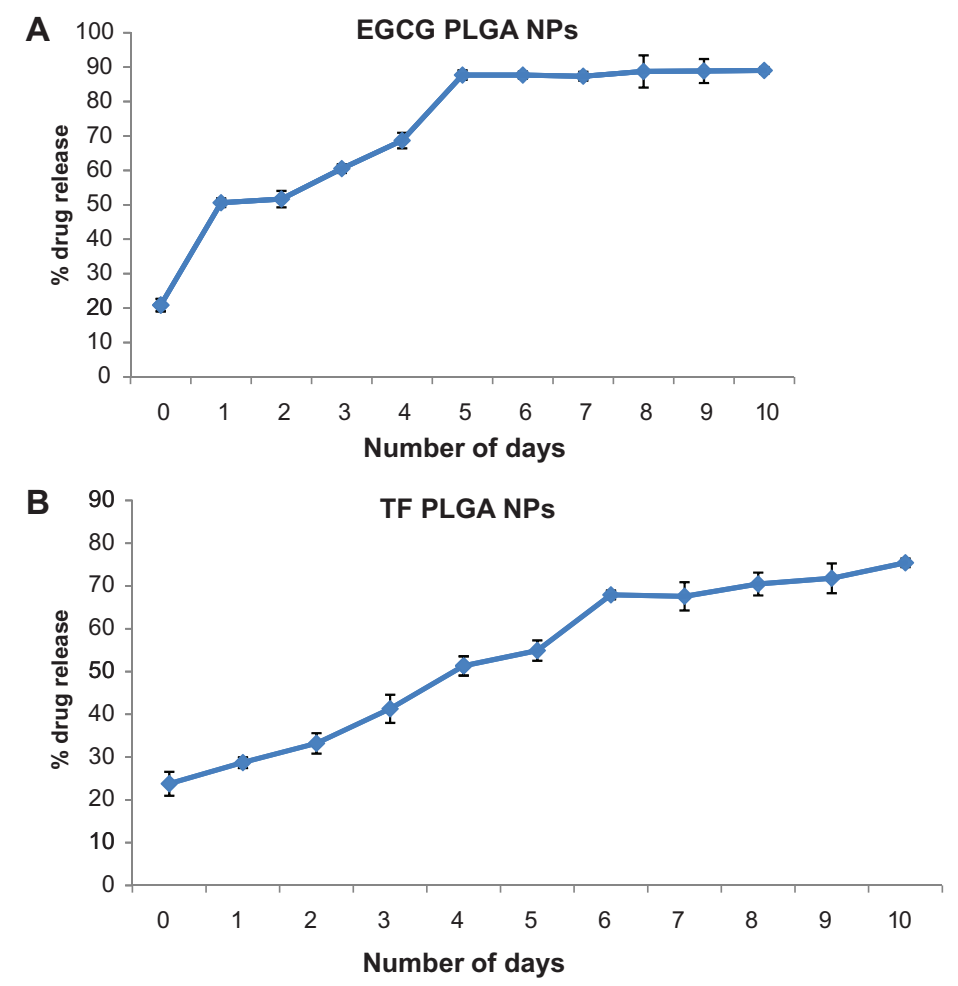

Figure 3 In-vitro release profile of EGCG (A) and TF (B) PLGA-NPs.

Note: Values are represented as mean \pm standard deviation.

Abbreviations: EGCG, epigallocatechin-3-gallate; PLGA-NP, poly(lactide-co-glycolide) nanoparticle; TF, theaflavin.

time interval of 24 hours following the doses of TF or EGCG. the bulk counterpart. Similarly, with bulk EGCG (100 $\mu \mathrm{g} /$ Significant protection (45.34\%) was observed at the dose of mouse), $28.82 \%$ protection was observed, while EGCG$100 \mu \mathrm{g}$ /mouse of bulk TF in 24 hours (Figure 5), while TF- loaded PLGA-NPs at 5, 10, and $20 \mu \mathrm{g} / \mathrm{mouse}$ dose provided loaded PLGA-NPs at doses 5,10, and $20 \mu \mathrm{g}$ /mouse provided $51.28 \%, 57.63 \%$, and $63.40 \%$ protection, respectively, protection of $64.40 \%, 71.19 \%$, and $72.46 \%$, respectively, showing about a 32-fold dose-advantage over bulk EGCG. which clearly shows about a 30-fold dose-advantage over However, PLGA-loaded TF (Group XI) and EGCG (Group

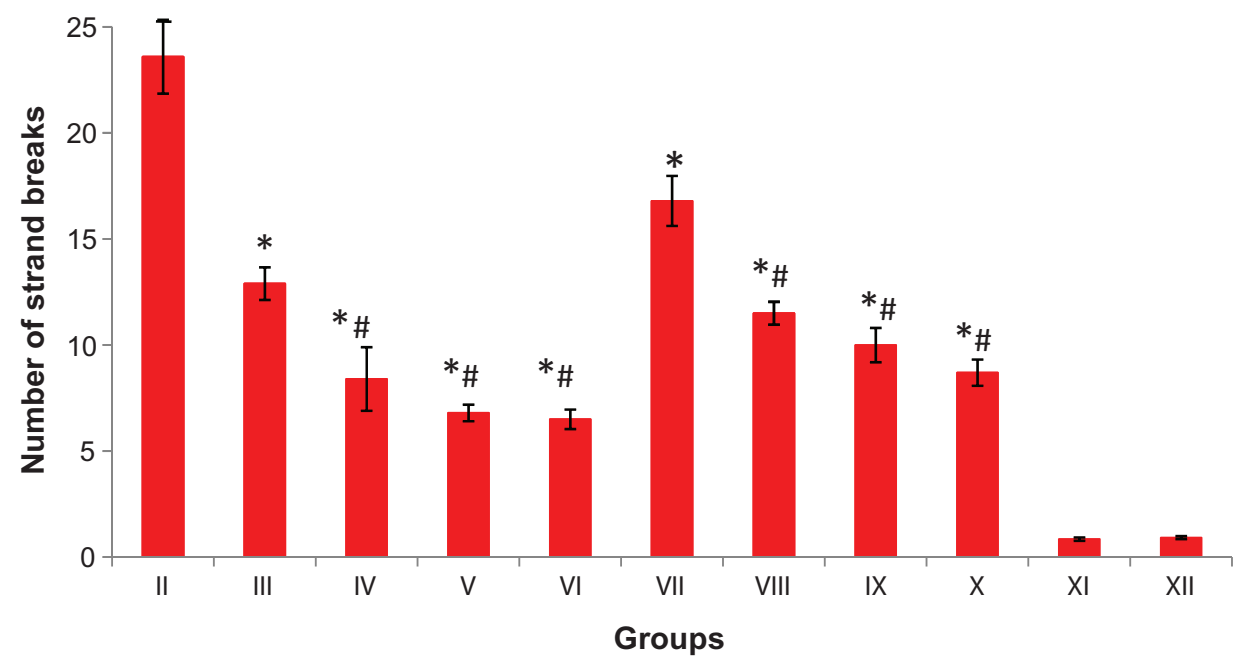

Figure 4 Reduction in DMBA-induced strand breaks by bulk and poly(lactide-co-glycolide)-loaded tea polyphenols.

Notes: Data shown is the mean \pm standard deviation of all the animals; *indicates significant reduction over DMBA-exposed Group II, $P<0.05$; "indicates significant effect of nanotized tea polyphenol over its bulk, $P<0.05$.

Abbreviation: DMBA, 7,12-dimethylbenzanthracene. 


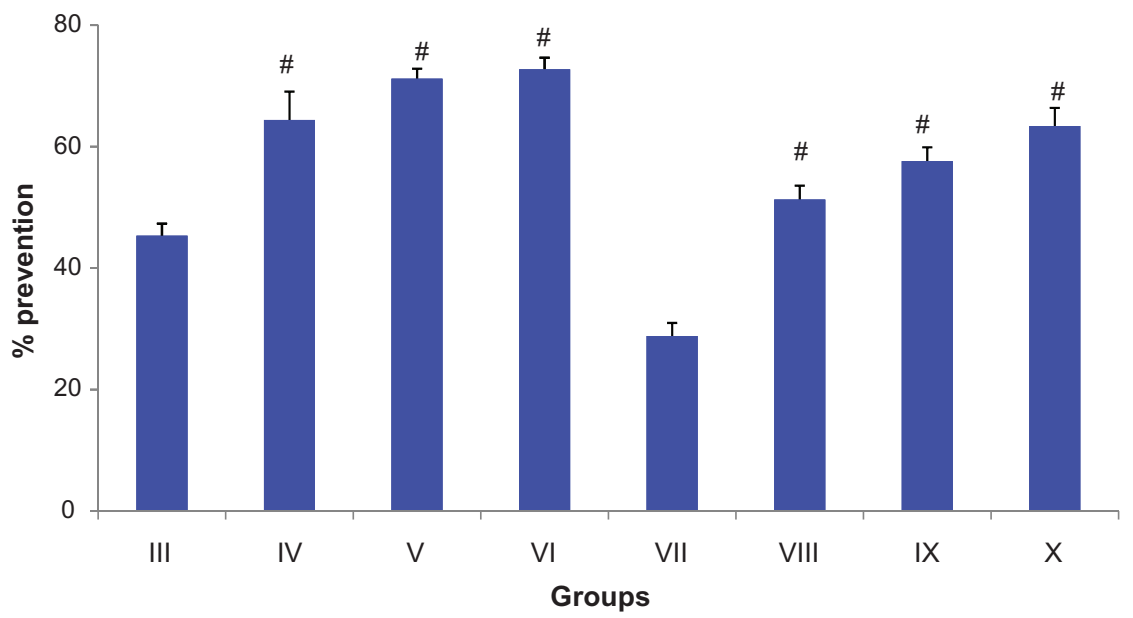

Figure 5 Percentage (\%) prevention in 7,I2-dimethylbenzanthracene-induced nick formation by bulk and poly(lactide-co-glycolide)-loaded tea polyphenols. Notes: Data shown is the mean \pm standard deviation of all the animals; \#indicates significant effect of nanotized tea polyphenol over its bulk, $P<0.05$.

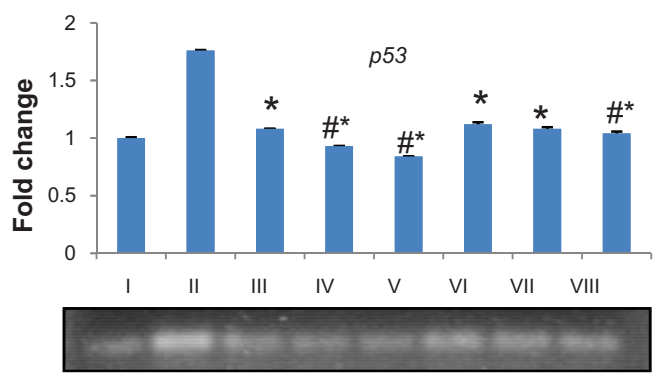

MDM2

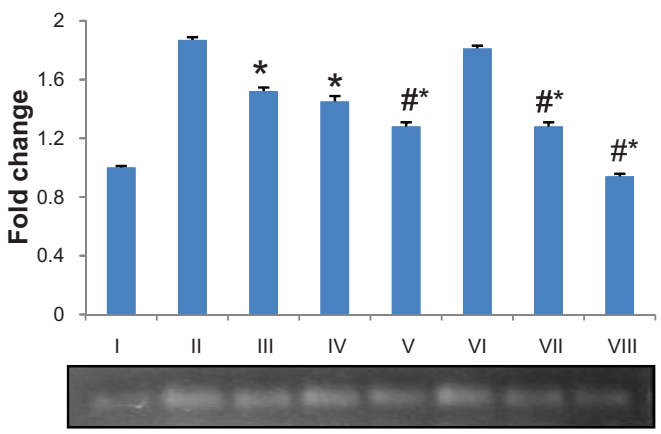

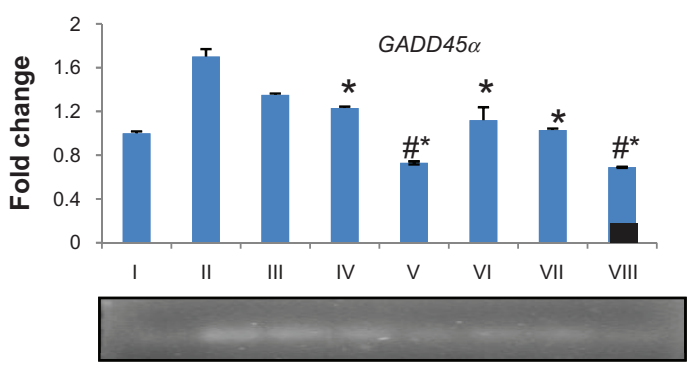

p21

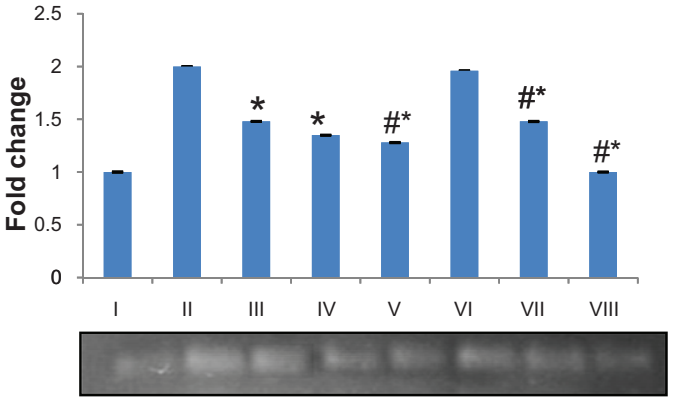

COX-2

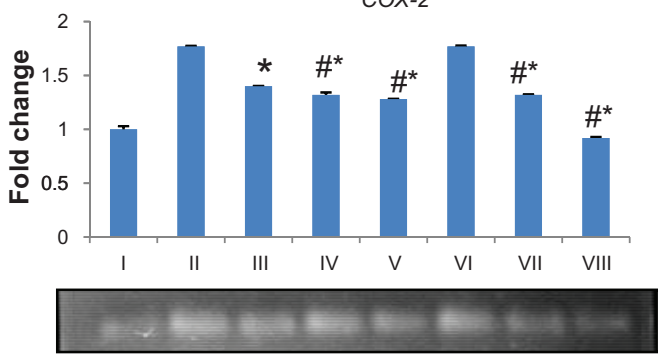

Figure 6 Effect of bulk and PLGA-loaded tea polyphenols on the transcription of DNA damage responsive genes. The pixel density of the specific mRNA expression bands was quantified by densitometry and expressed as a fold difference against $\beta$-actin.

Notes: Data shown is the result of three different experiments with similar results. The data were significant at *P $<0.05$ in comparison to Group II; \#indicates significant effect of nanotized tea polyphenol over its bulk, P < 0.05. Lanes: I, Control; II, DMBA (52 $\mu \mathrm{g} / \mathrm{mouse})$; III, TF (I00 $\mu \mathrm{g} / \mathrm{mouse})+\mathrm{DMBA}$; IV, TF-loaded PLGA-NPs (5 $\mu$ g/

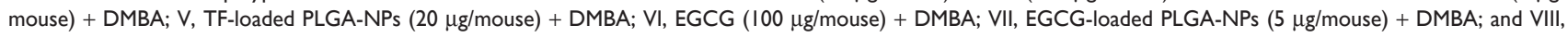
EGCG-loaded PLGA-NPs $(20 \mu \mathrm{g} /$ mouse $)+$ DMBA.

Abbreviations: DMBA, 7,12-dimethylbenzanthracene; EGCG, epigallocatechin-3-gallate; NP, nanoparticle; PLGA, poly(lactide-co-glycolide); TF, theaflavin. 

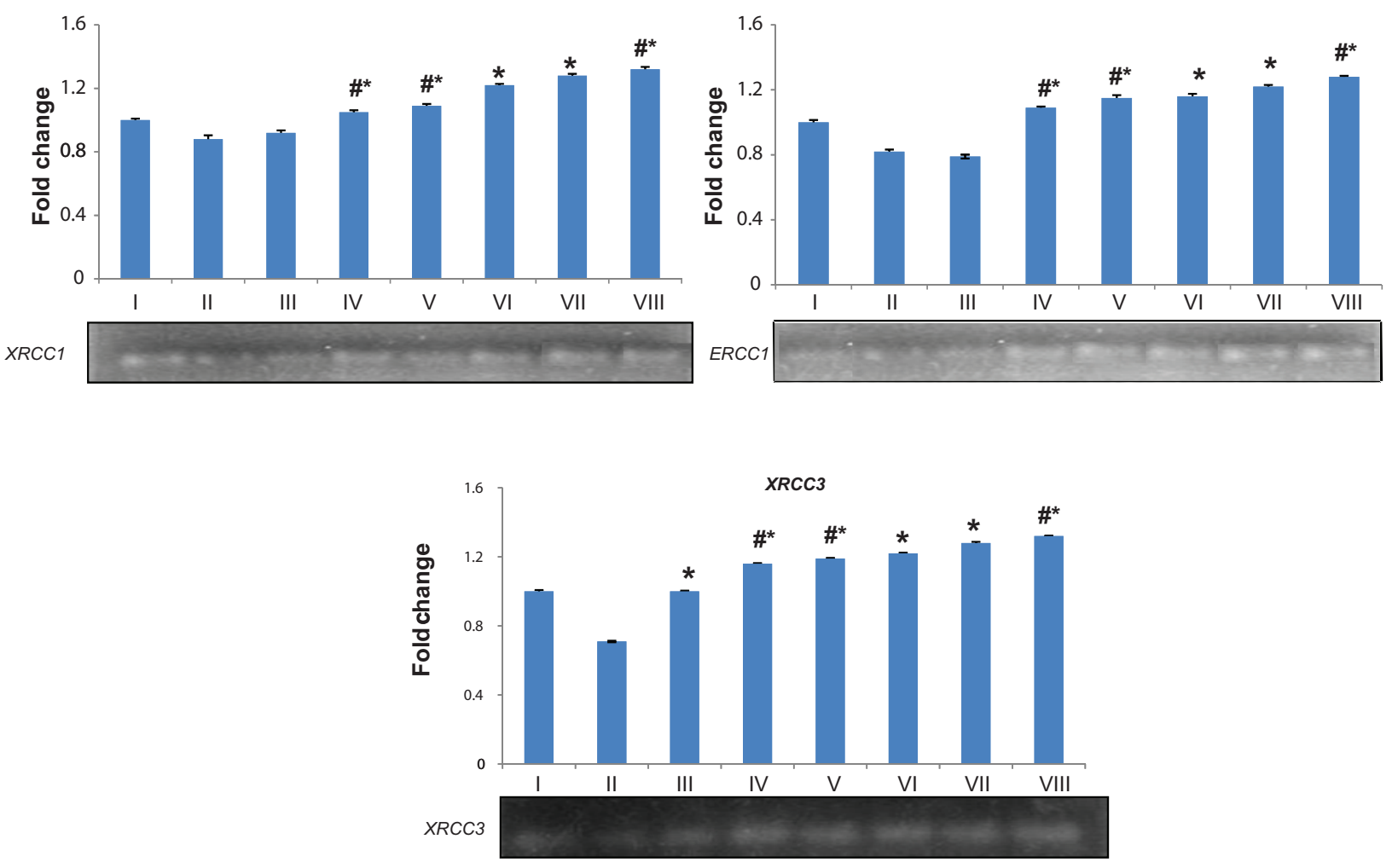

$\beta$-actin

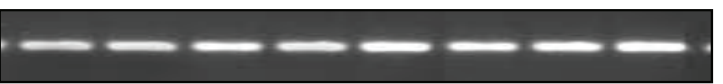

Figure 7 Effect of bulk and PLGA-loaded tea polyphenols on the transcription of DNA repair responsive genes. The pixel density of the specific mRNA expression bands was quantified by densitometry and expressed as a fold difference against $\beta$-actin.

Notes: Data shown is the result of three different experiments with similar results; the data were significant at *P $<0.05$ in comparison with Group II; $\#$ indicates significant effect of nanotized tea polyphenol over its bulk, P < 0.05. Lanes: I, Control; II, DMBA (52 $\mu \mathrm{g} / \mathrm{mouse})$; III, TF (I00 $\mu \mathrm{g} / \mathrm{mouse})+\mathrm{DMBA}$; IV, TF-loaded PLGA-NPs (5 $\mu \mathrm{g} /$ mouse) + DMBA; V, TF-loaded PLGA-NPs $(20 \mu \mathrm{g} / \mathrm{mouse})+$ DMBA; VI, EGCG (100 $\mu \mathrm{g} / \mathrm{mouse})+\mathrm{DMBA}$; VII, EGCG-loaded PLGA-NPs (5 $\mu \mathrm{g} / \mathrm{mouse})+\mathrm{DMBA}$, and VIII, EGCG-loaded PLGA-NPs $(20 \mu \mathrm{g} /$ mouse $)+$ DMBA.

Abbreviations: DMBA, 7,I2-dimethylbenzanthracene; EGCG, epigallocatechin-3-gallate; NP, nanoparticle; PLGA, poly(lactide-co-glycolide); TF, theaflavin.

XII) NPs alone failed to induce any significant DNA strand breaks (24 hours).

\section{Modulation of DNA damage/repair responsive genes by bulk and TF- or EGCG-loaded PLGA-NPs}

The comparative effects of bulk and nanotized tea polyphenols on the expression level of DNA damage ( $p 53, M D M 2$, $G A D D 45 \alpha$; growth arrest and DNA-damage-inducible $\alpha$ and $C O X-2)$ and repair-responsive genes (XRCC1; X-ray repair cross-complementing group $1, X R C C 3$; $\mathrm{X}$-ray repair cross-complementing group 3 , and $E R C C 1$; excision repair cross-complementing group 1) was investigated. mRNA levels of tested DNA damage and repair-responsive genes were more significantly enriched in TF- or EGCG-loaded PLGA-NPs as compared with bulk tea (Figures 6 and 7). Bulk TF (100 $\mu \mathrm{g} /$ mouse) reduced mRNA expression levels of DNA damage responsive genes $p 53, M D M 2, G A D D 45 \alpha$, and $C O X-2$ and increased expression of DNA repair gene $X R C C 3$ significantly $(P<0.05)$ compared with Group II. It also increased transcriptional levels of repair genes $X R C C 1$ and $E R C C 1$ and reduced the level of $p 21$, but not significantly. However, the lower doses of TF-loaded PLGA-NPs (1/20th and $1 / 5$ th of bulk) modulated expression levels of these genes more significantly $(P<0.05)$ than its bulk counterpart (Figures 6 and 7). TF-loaded PLGA-NPs significantly $(P<0.05)$ reduced mRNA level of DNA damage responsive genes ( $p 53, M D M 2, G A D D 45 \alpha, p 21$, and $C O X-2)$ and induced expression of DNA repair genes (XRCC1, XRCC3, and $E R C C 1)$ in a dose-dependent manner, compared with DMBA-exposed Group II. These findings showed significant $(P<0.05)$ dose advantage of TF-loaded PLGA-NPs over its bulk counterpart (Figures 6 and 7). Similarly, bulk EGCG (100 $\mu \mathrm{g} /$ mouse) reduced the expression of DNA damage responsive genes ( $p 53, p 21$, and GADD45 $\alpha$ ) 
and increased expression of DNA repair genes (XRCC1, $X R C C 3$, and ERCC1) significantly compared with Group II. It also reduced expression of $M D M 2$ and $C O X-2$ but in an insignificant manner. While lower doses of EGCG-loaded PLGA-NPs (1/20th and $1 / 5$ th of bulk) significantly $(P<0.05)$ modulated the mRNA levels of tested DNA damage and repair responsive genes in comparison to Group II. These results further support the remarkable dose advantage of EGCG-loaded PLGA-NPs over its bulk tea polyphenol. These results clearly demonstrate that topical application of PLGA-loaded tea polyphenols prior to DMBA exposure led to more significant protection compared with bulk TF and EGCG treatment.

\section{Discussion}

In the present study, TF- and EGCG-loaded PLGA-NPs were formulated (using the double emulsion technique) with an entrapment efficacy of $\sim 18 \%$ and $26 \%$, and particle size of 129.60 and $127.20 \mathrm{~nm}$, respectively. A low entrapment efficacy was obtained with tea polyphenols as its well known that the entrapment of hydrophilic drug substances inside the polymer is quite a difficult task. ${ }^{32}$ The main reason for this problem is that the hydrophilic drug substances have a very low affinity with polymers. In addition, the interactions between the polymer and hydrophilic substances are weak, and the hydrophilic substance has a tendency to move from the organic phase to the outer aqueous phase and not in the precipitating NPs. ${ }^{32-34}$ The zeta potential value is an important particle characteristic as it can influence both particle stability as well as particle properties. Theoretically, more pronounced zeta potential values, being positive or negative, tend to stabilize particle suspension. The electrostatic repulsion between particles with the same electric charge prevents the aggregation of the sphere. ${ }^{35}$ In the present study, zeta potential for TF-loaded PLGA-NPs and EGCG-loaded PLGA-NPs was -20.20 and -24.50 , respectively; the negative value of zeta potential for these NPs indicating the formation of stable NPs. Further, the potential of PLGA-loaded TF or EGCG NPs versus bulk tea against DMBA induced DNA damage in mouse skin tissue was compared. Topical application of TF- (Group XI) and EGCG- (Group XII) loaded PLGA-NPs alone, failed to induce significant DNA strand breaks, confirming the nontoxic nature of these tea NPs. Furthermore, PLGA-loaded tea polyphenols reduced DMBA-induced DNA damage more efficiently and have $\sim 30$-fold dose-advantage over bulk tea polyphenols. Previous studies also showed that PLGA encapsulated EGCG-NPs have $\sim 10$-fold dose-advantage over their bulk counterpart in both in vivo (Xenograft) and in vitro systems. ${ }^{36}$ Moreover, the findings of the present study confirm that lower doses of nanotized tea polyphenols have significant potential for induction of DNA repair genes (XRCC1, XRCC1, and ERCC3) and suppression of DNA damage responsive genes ( $p 53, p 21$, $M D M 2$, GADD45 $\alpha$, and $C O X-2)$ compared with respective bulk $(P<0.05)$. In the present study, the expressions of eight genes were measured; five of the eight are involved in DNA damage, and the remaining are involved in the repair process. ${ }^{37}$ The genes $p 53$ and $p 21$ are involved in cell-cycle arrest and induction of apoptosis after the onset of DNA damage and are documented to be induced by DMBA and have a significant role in skin carcinogenesis. ${ }^{38-40} M D M-2$ is a gene for ubiquitin ligase, which binds $p 53$ and mediates its proteasomic cleavage, but is also upregulated by $p 53$ at mRNA level. ${ }^{38} G A D D 45 \alpha$ is modulated by $p 53$ and plays a central role in inducing $\mathrm{G} 2 / \mathrm{M}$ arrest after genotoxic stress. ${ }^{41}$ $C O X-2$ is an inflammatory gene, plays major roles in carcinogenesis, tumor growth, and metastasis. ${ }^{42}$ ERCC1, XRCC1, and $X R C C 3$ genes are involved in excision repair or doublestrand break repair. ${ }^{43}$ It can be assumed that the better efficacy of PLGA-loaded tea polyphenols may be due to the enhanced penetration capability of NPs across the cell surface (bulk materials have to face several barriers). ${ }^{16,17}$

It is well known that mutations in somatic cells play a central role in cancer initiation and progression. ${ }^{44}$ The promising findings of the present study suggest that the concept of nanochemoprevention possesses strong merit and rationale for conducting more studies in other animal models with relevance to human diseases.

\section{Acknowledgments}

The authors are thankful to CSIR, New Delhi, for providing Senior Research Fellowship to Mr Amit Kumar Srivastava. They are thankful to Mr Syed H N Naqvi, technical staff, for providing help in animal bioassay. The authors are also thankful to CSIR, New Delhi, for funding this work from NWP-17 and SIP-08.

\section{Disclosure}

The authors report no conflicts of interest in this work.

\section{References}

1. Siomi H. Transposable elements, RNA silencing, and their impacts on the genome throughout evolution. Uirusu. 2008;58(1):55-60.

2. Triampoa W, Triampob D, Ming Tangb I, Lenburyc Y. The stochastic model of non-equilibrium mutagen-induced alterations of DNA: Implication to genetic instability in cancer. Biosystems. 2007;90(3): 870-880. 
3. Graham HN. Green tea composition, consumption, and polyphenol chemistry. Prev Med. 1992;21(3):334-350.

4. Weisburger JH. Tea and health: a historical perspective. Cancer Lett. 1997;114(1-2):315-317.

5. McKay DL, Blumberg JB. The role of tea in human health: an update. $J$ Am Coll Nutr. 2002;21(1):1-13.

6. Leone M, Zhai D, Sareth S, Kitada S, Reed JC, Pellecchia M. Cancer prevention by tea polyphenols is linked to their direct Inhibition of antiapoptotic Bcl-2-family proteins. Cancer Res. 2003;63(23):8118-8121.

7. Ahmad N, Mukhtar H. Green tea polyphenols and cancer: biological mechanisms and practical implications. Nutr Rev. 1999;57(3):78-83.

8. Yang CS, Maliaka P, Meng X. Inhibition of carcinogenesis by tea. Annu Rev Pharmacol Toxicol. 2002;42(1):25-54.

9. Choudhury SR, Balasubramanian S, Chew YC, Han B, Marquez VE, Eckert RL. (-)-Epigallocathechin-3-gallate and DZNep reduce polycomb protein level via a proteasome-dependent mechanism in skin cancer cells. Carcinogenesis. 2011;32(10):1525-1532.

10. Patel R, Krishnan R, Ramchandani A, Maru G. Polymeric black tea polyphenols inhibit mouse skin chemical carcinogenesis by decreasing cell proliferation. Cell Prolif. 2008;41(3):532-553.

11. Roy P, George J, Srivastava S, Tyagi S, Shukla Y. Inhibitory effects of tea polyphenols by targeting cyclooxygenase-2 through regulation of nuclear factor kappa B, Akt and p53 in rat mammary tumors. Invest New Drugs. 2011;29(2):225-231.

12. Prasad S, Kaur J, Roy P, Kalra N, Shukla Y. Theaflavins induce $\mathrm{G} 2 / \mathrm{M}$ arrest by modulating expression of $\mathrm{p} 21 \mathrm{waf} 1 / \mathrm{cip} 1$, cdc25C and cyclin B in human prostate carcinoma PC-3 cells. Life Sci. 2007;81(17-18):1323-1331.

13. Siddiqui IA, Afaq F, Adhami VM, Mukhtar H. Prevention of prostate cancer through custom tailoring of chemopreventive regimen. Chem Biol Interact. 2008;171(2):122-132.

14. Nishiyama N. Nanomedicine: nanocarriers shape up for long life. Nat Nanotechnol. 2007;2(4):203-204.

15. Demming A. Big challenges and nanosolutions. Nanotechnology. 2011;22(29):290201.

16. Hu S, Zhang Y. Endostar-loaded PEG-PLGA nanoparticles: in vitro and in vivo evaluation. Int J Nanomedicine. 2010;24:5:1039-1048.

17. Yallapu MM, Gupta BK, Jaggi M, Chauhan SC. Fabrication of curcumin encapsulated PLGA nanoparticles for improved therapeutic effects in metastatic cancer cells. J Colloid Interface Sci. 2010;351(1):19-29.

18. Jain RA. The manufacturing techniques of various drug loaded biodegradable poly(lactide-co-glycolide) (PLGA) devices. Biomaterials. 2000;21(23):2475-2490.

19. Green A, Whiteman D, Frost C, Battistutta D. Sun exposure, skin cancers and related skin conditions. J Epidemiol. 1999;9(6 Suppl):S7-S13.

20. Gupta S, Mukhtar H. Chemoprevention of skin cancer through natural agents. Skin Pharmacol. Appl Skin Physiol. 2001;14(6):373-385.

21. Rockley PF, Trieff N, Wagner Jr RF, Tyring SK. Nonsunlight risk factors for malignant melanoma. Part I: chemical agents, physical conditions, and occupation. Int J Dermatol. 1994;33(6):398-406.

22. Jemal A, Siegel R, Ward E, et al. Cancer statistics 2008. CA Cancer J Clin. 2008;58(2):71-96.

23. Murray CJL, Lopez AD. The Global Burden of Disease: a Comprehensive Assessment of Mortality and Disability from Diseases, Injuries and Risk Factors in 1990 and Projected to 2020. Cambridge: Harvard University Press; 1996.

24. Lyle BJ, Mares-Perlman JA, Klein BE, Klein R, Greger JL. Supplement users differ from nonusers in demographic, lifestyle, dietary and health characteristics. J Nutr. 1998;128(12):2355-2362.
25. Esmaeili F, Hosseini-Nasr M, Rad-Malekshahi M, Samadi N, Atyabi F, Dinarvand R. Preparation and antibacterial activity of rifampicinloaded poly lactide-co-glycolide nanoparticles. Nanomedicine. 2007;3(2):161-167.

26. Swami A, Aggarwal A, Pathak A, Patnaik S, Kumar P, Gupta KC. Imidazolyl-PEI modified nanoparticles for enhanced gene delivery. Int J Pharm. 2007;335(1-2):180-192.

27. Khan TH, Prasad L, Anuradha, Sultana S. Soy isoflavones inhibits the genotoxicity of benzo(a)pyrene in Swiss albino mice. Hum Exp Toxicol. 2005;24(3):149-155.

28. Nigam N, Prasad S, Shukla Y. Preventive effects of lupeol on DMBA induced DNA alkylation damage in mouse skin. Food Chem Toxicol. 2007;45(11):2331-2335.

29. Arora A, Siddiqui IA, Shukla Y. Modulation of p53 in 7,12dimethylbenz[a]anthracene induced skin tumors by diallyl sulphide in Swiss albino mice. Mol Cancer Ther. 2004;3(11):1459-1466.

30. Gopferich A. Mechanisms of polymer degradation and erosion. Biomaterials. 1996;17(2):103-114.

31. Vert M, Li S, Garreau H. More about degradation of LA/GA derived matrices in aqueous media. $J$ Cont Rel. 1991;16(1-2):15-26.

32. Allémann E, Gurny R, Doelker E. Drug-loaded nanoparticles preparation methods and drug targeting issues. $J$ Pharm Biopharm. 1993;39(5):173-191.

33. Barichello JM, Morishita M, Takayama K, Nagai T. Encapsulation of hydrophilic and lipophilic drugs in PLGA nanoparticles by the nanoprecipitation method. Drug Dev Ind Pharm. 1999;25(4):471-476.

34. Govender T, Stolnik S, Garnett MC, Illum L, Davis SS. PLGA nanoparticles prepared by nanoprecipitation: drug loading and release studies of a water soluble drug. J Control Release. 1999;57(2):171-185.

35. Feng S, Huang G. Effects of emulsifiers on the controlled release of paclitaxel (Taxol) from nanospheres of biodegradable polymers. $J$ Control Release. 2001;71(1):53-69.

36. Siddiqui IA, Adhami VM, Bharali DJ, et al. Introducing nanochemoprevention as a novel approach for cancer control: proof of principle with green tea polyphenol epigallocatechin-3-gallate. Cancer Res. 2009;69(5):1712-1716.

37. Hreljac I, Zajc I, Lah T, Filipi M. Effects of model organophosphorous pesticides on DNA damage and proliferation of HepG2 cells. Environ Mol Mutagen. 2008;49(5):360-367.

38. Vogelstein B, Lane D, Levine AJ. Surfing the p53 network. Nature. 2000;408(6810):307-310.

39. Wang S, El-Deiry WS. p73 or p53 regulates human p53 transcription to maintain cell cycle checkpoints. Cancer Res. 2006;66(14):6982-6989.

40. El-Deiry WS, Tokino T, Velculescu VE, et al. WAF1 a potential mediator of p53 tumor suppression. Cell. 1993;75(4):817-825.

41. Hollander MC, Alamo I, Jackman J, Wang MG, McBride OW, Fornace AJ Jr. Analysis of the mammalian gadd 45 gene and its response to DNA damage. J Biol Chem. 1993;268(32):24385-24393.

42. Liu H, Xiao J, Yang Y, et al. COX-2 expression is correlated with VEGF-C, lymphangiogenesis and lymph node metastasis in human cervical cancer. Microvasc Res. 2011;82(2):131-140.

43. Wang A, Wolf DC, Sen B, et al. Dimethylarsinic acid in drinking water changed the morphology of urinary bladder but not the expression of DNA repair genes of bladder transitional epithelium in F344 rats. Toxicol Pathol. 2009;37(4):425-437.

44. Srivastava S, Verma M, Henson DE. Biomarkers for early detection of colon cancer. Clinical Cancer Res. 2001;7(5):1118-1126. 


\section{Supplementary table}

Table I Conditions for PCR amplification of the genes studied

\begin{tabular}{|c|c|c|c|c|}
\hline Target gene for mouse & PCR primers $\left(5^{\prime}-3^{\prime}\right)$ & Annealing temp $\left({ }^{\circ} \mathrm{C}\right)$ & Number of cycles & Product size (bp) \\
\hline \multirow[t]{2}{*}{ p53 } & F: AGGACTTCCGAAAGCTAGGC & 58 & 35 & 131 \\
\hline & R: TTGACTGTGATCTGGCGAAG & & & \\
\hline \multirow{2}{*}{ MDM2 } & F: GAAGGCCGAACAGACGCCCC & 58 & 35 & 195 \\
\hline & R: TTAGGCCGCCCCTGGCAGAT & & & \\
\hline \multirow[t]{2}{*}{$p 21$} & F: TACCCAACTACCAGCTGTGGGGT & 60 & 35 & 279 \\
\hline & R: CGGCGTCTCCGTGACGAAGT & & & \\
\hline \multirow[t]{2}{*}{ GADD $45 \alpha$} & F: AGGATGGACACGGTGGGCGA & 58 & 35 & 147 \\
\hline & R: TTCGTCAGCAGCCAGCAGGC & & & \\
\hline \multirow[t]{3}{*}{ COX -2} & F: TCCGAGCTGTGCTGCTCTGC & 60 & 35 & 626 \\
\hline & R: GCCCAGTCCTCGGGTGAACC & & & \\
\hline & F: GCTTGCGCACTGAGTCCCGT & 60 & 35 & 161 \\
\hline \multirow[t]{2}{*}{$X R C C I$} & R: GCTGCTGCAGGACACGACGT & & & \\
\hline & F: GCCCAGAGGGCGTCTCCGTA & 60 & 35 & 877 \\
\hline \multirow[t]{2}{*}{$X R C C 3$} & R: GCAGGATTGCCACAGCGGGT & & & \\
\hline & F: GCTTGCGCACTGAGTCCCGT & 60 & 35 & 161 \\
\hline ERCCI & R: GCTGCTGCAGGACACGACGT & & & \\
\hline
\end{tabular}

Abbreviations: $F$, forward; $P C R$, polymerase chain reaction; $R$, reverse.

International Journal of Nanomedicine

\section{Publish your work in this journal}

The International Journal of Nanomedicine is an international, peerreviewed journal focusing on the application of nanotechnology in diagnostics, therapeutics, and drug delivery systems throughout the biomedical field. This journal is indexed on PubMed Central, MedLine, CAS, SciSearch $\AA$, Current Contents ${ }^{\circledR} /$ Clinical Medicine,

\section{Dovepress}

Journal Citation Reports/Science Edition, EMBase, Scopus and the Elsevier Bibliographic databases. The manuscript management system is completely online and includes a very quick and fair peer-review system, which is all easy to use. Visit http://www.dovepress.com/ testimonials.php to read real quotes from published authors. 